CLIMATE CHANGE

\section{Knowledge alters public perception}

An awareness of the causes of climate change, rather than its consequences or physical characteristics, can increase the public's concern about global warming.

Past studies have suggested that values are more important than knowledge in influencing public perception about climate-change risks. Jing Shi of the Swiss Federal Institute of Technology in Zurich and her colleagues conducted an online survey of roughly 400 people in each of six countries: Canada, China, Germany, Switzerland, the United Kingdom and the United States, controlling for cultural views and values. The results suggest that people are more likely to be concerned about global warming if they understand its basic causes, such as human activities. However, knowledge about the physical aspects of the climate system itself (for example, that burning oil produces carbon dioxide) was correlated with a reduction in concern.

Tailored climate-education programmes might sway public attitudes, the authors say. Nature Clim. Change http://dx.doi. org/10.1038/nclimate2997 (2016)

\section{IMMUNOLOGY}

\section{Why older people are prone to flu}

Minimizing responses from a type of immune cell could help to treat influenza in old people.

The vast majority of influenza deaths are among older people. To find out what makes them vulnerable, Akiko Iwasaki at Yale School of Medicine in New Haven, Connecticut, and her colleagues compared white blood cells from healthy volunteers in their

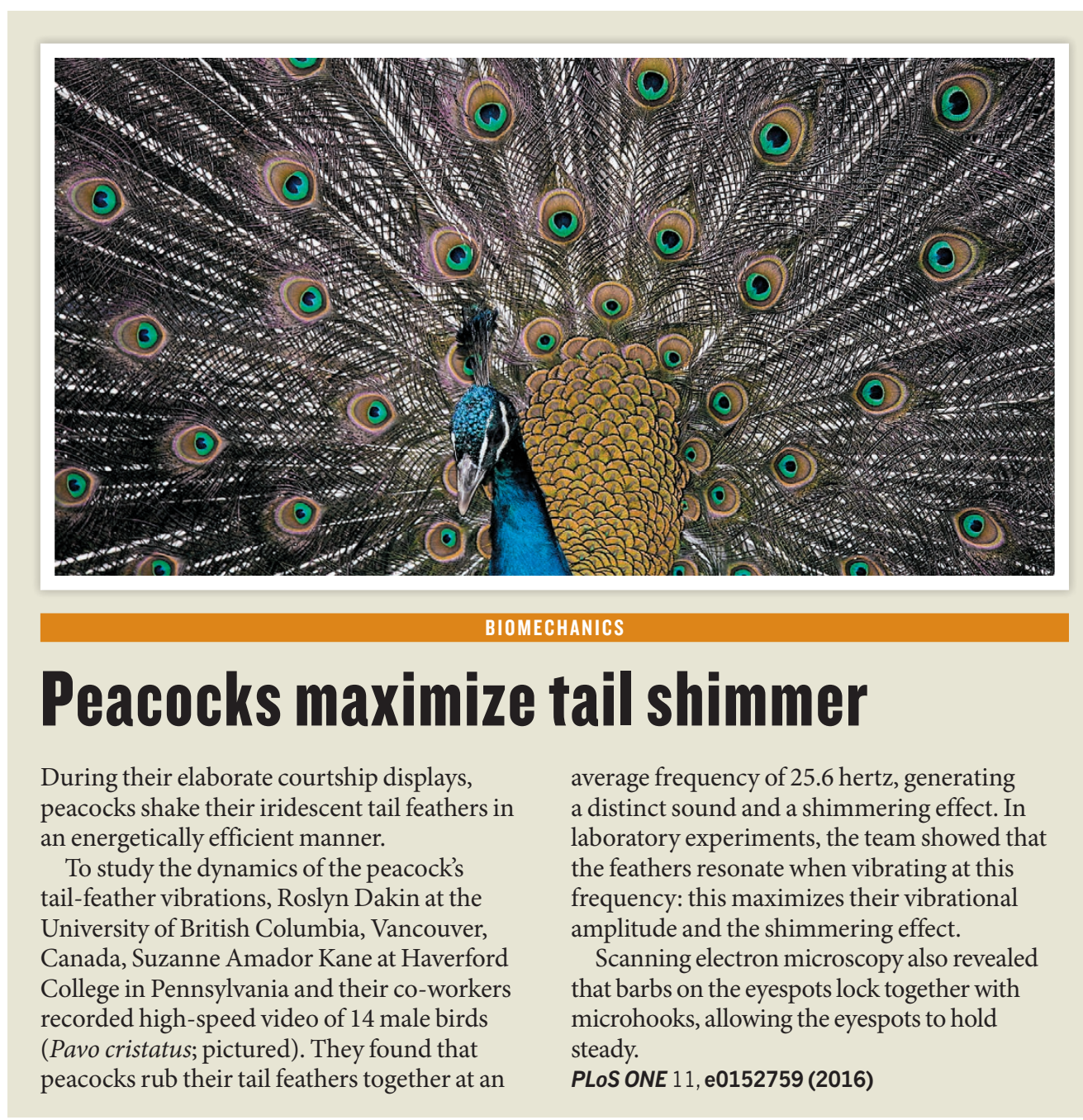

20 s with those from people over 65 . When infected with flu virus, cells from the older group produced lower levels of virusfighting proteins called type 1 interferons.

In mice, knocking out two genes (Mavs and Tlr7) that help to trigger interferon responses made the animals more vulnerable to both flu and bacterial lung infections. But deleting the Casp1/11 genes, which help to activate immune cells called neutrophils, protected the mice. The authors suggest that reducing the inflammatory responses of these cells could be a way to treat flu in older adults. Science 352, 463-466 (2016)

\section{BEHAVIOURAL ECOLOGY}

\section{Single-celled life can learn}

Slime moulds show signs of learning, suggesting that the process does not require nerves and may have evolved early in the history of life.

In a simple form of learning called habituation, an organism learns to ignore continuous stimuli over time. Audrey Dussutour and her team at Toulouse University, France, observed single-celled slime moulds (Physarum polycephalum) crossing a bridge in a Petri dish. The bridges were treated with repellent chemicals, either quinine or caffeine, or left untreated. Cells approached and crossed untreated bridges three times faster than cells crossing treated ones. The cells became habituated to treated bridges, crossing them faster after 5 days. However, after 2 days of no chemicals, the organisms' aversion to caffeine or quinine returned. And cells that were habituated to quinine still showed aversion to caffeine, and vice versa, ruling out sensory fatigue or adaptation.

The study suggests that simple learning processes pre-date neuron evolution. Proc. R. Soc. B 283, 20160446 (2016) 